\title{
Prevalence of COPD and respiratory symptoms associated with biomass smoke exposure in a suburban area
}

This article was published in the following Dove Press journal: International Journal of COPD

\author{
Alejandra Ramírez-Venegas' \\ Mónica Velázquez-Uncal' \\ Rosaura Pérez-Hernández ${ }^{2}$ \\ Nicolás Eduardo Guzmán- \\ Bouilloud' \\ Ramcés Falfán-Valencia ${ }^{3}$ \\ María Eugenia Mayar-Maya ${ }^{4}$ \\ Adrian Aranda-Chávez' \\ Raúl H Sansores ${ }^{5}$ \\ 'Tobacco Smoking and COPD \\ Research Department, Instituto \\ Nacional de Enfermedades \\ Respiratorias Ismael Cosio Villegas, \\ Mexico City, Mexico; ${ }^{2}$ Research \\ Department of Tobacco Smoking, \\ Centro de Investigacion de Salud \\ Poblacional, Instituto Nacional de \\ Salud Pública, Cuernavaca, Mexico; \\ ${ }^{3} \mathrm{HLA}$ Laboratory, Instituto Nacional \\ de Enfermedades Respiratorias Ismael \\ Cosio Villegas, Mexico City, Mexico; \\ ${ }^{4}$ Medical Attention Department, \\ Instituto Nacional de Enfermedades \\ Respiratorias Ismael Cosio Villegas, \\ Mexico City, Mexico; ${ }^{5}$ Medica Sur \\ Clinic \& Foundation, Mexico City, \\ Mexico
}

Introduction: Biomass smoke exposure (BSE) is a recognized cause of COPD particularly in rural areas. However, little research has been focused on BSE in suburban areas.

Objective: The aim of this study was to determine the prevalence of COPD, respiratory symptoms (RS) and BSE in women living in a suburban area of Mexico City exposed to BSE.

Methods: A cross-sectional epidemiological survey of a female population aged $>35$ years was performed using a multistage cluster sampling strategy. The participants completed questionnaires on RS and COPD risk factors. The COPD prevalence was based on the postbronchodilator forced expiratory volume in the first second $\left(\mathrm{FEV}_{1}\right)$ /forced vital capacity $(\mathrm{FVC})$ ratio. Of the 1,333 women who completed the respiratory questionnaires, spirometry data were obtained from 1,190, and 969 of these were scored as A-C.

Results: The prevalence of BSE was $47 \%$, and the estimated prevalence of COPD was $2.5 \%$ for the total population ( $n=969)$ and $3.1 \%$ for those with BSE only. The spirometry and oximetry values were significantly lower in women with greater exposure levels. The prevalence of RS (cough, phlegm, wheezing and dyspnea) was significantly higher in the women with BSE compared to those without exposure. We concluded that the association of COPD with biomass exposure is not only a rural phenomenon but also may be observed in the suburban areas of the big cities.

Keywords: risk factor, gender, airway obstruction

\section{Introduction}

The prevalence of COPD is increasing ${ }^{1,2}$ and may be even 2-fold higher than reported if underdiagnosis and non-smoking causes of COPD are considered. ${ }^{3}$ In developing countries, the prevalence has been estimated to be between $7.8 \%$ and $13 \%$ depending on whether population-based studies or screening among smokers is considered. ${ }^{4,5}$ Exposure to biomass smoke has been reported to be an additional risk factor mainly in women who use biomass fuel to cook or warm their homes. ${ }^{6}$ However, men may also develop the disease. ${ }^{7}$ Therefore, the prevalence of COPD may be even greater than that previously estimated. ${ }^{8}$ The association of COPD with biomass smoke exposure (BSE) has been mainly described in the rural areas where the use of these fuels is associated with poverty and lack of electricity. The presence of the disease is directly associated with biomass exposure rather than place or location, either rural or suburban. However, the relationship between the prevalence of COPD and exposure to biomass smoke in suburban areas, where poverty is lower and electricity is available, has not been explored, perhaps due to an assumption that no biomass exposure occurs.
Correspondence: Raúl H Sansores Medica Sur Clinic \& Foundation, Puente de Piedra I50 Toriello Guerra, Tlalpan, ZC 14050 Mexico City, Mexico

$\mathrm{Tel}+5255$ 5I7I 5107

$\mathrm{Fax}+525551716292$

Email raulsansores@yahoo.com.mx
International Journal of COPD 20|8:13 |727-1734

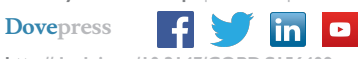

http://dx,doi.org/10.2147/C (c) (1) (-) 2018 Ramirez-Venegas et al. This work is published and licensed by Dove Medical Press Limited. The full terms of this license are available at https://www.dovepress.com/terms.php C. hereby accept the Terms. Non-commercial uses of the work are permitted without any further permission from Dove Medical Press Limited, provided the work is properly attributed. For permission for commercial use of this work, please see paragraphs 4.2 and 5 of our Terms (https://www.dovepress.com/terms.php). 
Therefore, the aim of this study was to determine the prevalence of COPD and respiratory symptoms (RS) in women who live in these areas of Mexico City as well as the prevalence of biomass exposure in suburban areas.

\section{Methods Study design}

This was a population-based cross-sectional epidemiological survey of COPD. A multistage cluster sampling strategy was used in a population aged $>35$ years in a suburban area of Mexico City.

\section{Setting}

In political terms, Mexico City is considered to be 1 of the 32 states comprising the country and is divided into 17 counties named as Delegations. One of them is Tlalpan, which is located in the south of the city and borders another state named Morelos. This study was performed in Tlalpan, which is an area with $\sim 700,000$ inhabitants. The target population was randomly selected from 8 locations in Tlalpan bordering, but not belonging to the rural areas of Morelos. These 8 locations are, strictly speaking, part of Mexico City and have public services (electricity, gas, water, telephone lines, TV, Internet, public transport, etc.). Specifically, in Mexico, the suburban areas have housed villages that originally belonged to the rural area, with deeply rooted traditions, and in this sense, the use of fuel with biomass is very common. Later on, these villages remained practically inside or next to the city, with some own services of the cities, but remaining with uses and customs of their parents and grandparents. On the other hand, in these same areas, $30 \%$ of women from rural areas or others migrated but those who migrated were younger people. However, for this study, the locations were considered to be suburban on the basis of being settled within the big city. Most of their inhabitants are originally from those rural areas of Morelos and the expansion of Mexico City made them set up their homes within an area belonging to Tlalpan, where they currently have the political rights and duties associated with Mexico City and specifically to the Delegation of Tlalpan.

\section{Ethics approval and informed consent}

This original research protocol and informed consent were approved by the ethics and research committee of the National Institute of Respiratory Diseases "Ismael Cosío Villegas" of Mexico City, with approval reference number C-1313. All women participants signed an informed consent for both interviews and spirometry.

\section{Study population}

The study involved women $>35$ years of age and included at least 1 woman from each respondent home. One of the objectives of including a population $<40$ years was to look at the prevalence of RS and the possibility to find patients with early COPD. The inclusion criteria were as follows: 1) to have their permanent residence in 1 of the 8 locations of Tlalpan for at least 20 years prior to this study, 2) to be willing to perform spirometry and 3) to sign the consent form. Exclusion criteria for the study included mental illness and refusal to perform spirometry or to sign the informed consent. Exclusion criteria for spirometry also included recent thoracic or abdominal surgery, myocardial infarction, eye surgery (or retinal detachment), diagnosis of current and history of past tuberculosis or pregnancy. Subjects with a pulse rate of $>120$ beats per minute were also excluded. Asthma subjects were identified and eliminated, if in the spirometry, they presented postbronchodilator response of $12 \%$ or higher (provided it is $\geq 200 \mathrm{~mL}$ ) in forced expiratory volume in the first second ( $\mathrm{FEV}_{1}$ or forced vital capacity $\left.[\mathrm{FVC}]\right)$ from the baseline spirometry and $\mathrm{FEV}_{1} / \mathrm{FVC}>70 \%$.

\section{Sample size}

Considering a power of $95 \%$ and a margin error of $5 \%$ for an expected prevalence of $7 \%$ of COPD according to the PLATINO study ${ }^{4}$ and based on the same characteristics population, a total of 1,200 households were estimated to be required for the completion of the individual questionnaires. Assuming an estimated response rate of $70 \%$, visiting 2,600 homes from the 8 locations was planned.

\section{Procedure}

A representative sample of adult women living in the suburban areas of each site of Tlalpan was included using a multistage cluster sampling strategy. Within each location of 15-block area, blocks were randomly selected with selection probability proportional to the number of households. On the next level, once households were identified, a systematic sampling selection was performed on site. At least 325 homes were visited in each of the 8 locations in which the survey was conducted. The number of missing home visits varied among the 8 studied locations (up to $10 \%$ ), due to the mobility of families and unforeseeable factors such as floods, intense rain, natural disasters or other force majeure.

\section{Outcomes}

The main outcome of the study was to determine the prevalence of COPD in women in the suburban areas of Mexico 
City as measured by spirometry using the definition of a postbronchodilator $\mathrm{FEV}_{1} / \mathrm{FVC}<0.70 .^{2}$ Secondary outcomes included the prevalence of biomass exposure and RS associated with biomass exposure.

\section{Procedures}

Using standardized procedures by trained interviewers, the following ordered steps were conducted at home of each respondent woman: 1) individual questionnaire, 2) oximetry, height and weight measurements, 3) waist circumference measurement and 4) pre- and postbronchodilator spirometries. Data were stored on an online platform designed for this study.

Household questionnaire includes items to precise location and identification of the households and participants. The individual questionnaire contained a wide battery of questions designed to obtain data to support the study on the prevalence of COPD associated with exposure to biomass smoke as well as tobacco smoking. Their general airway health conditions were also queried and in particular on smoking and socioeconomic status.

\section{Biomass exposure}

The instrument contains items to determine the frequency of exposure of the women to biomass smoke in terms of total years and total hours during the day. Therefore, the cumulative exposure was expressed as hours/years, meaning the product of the number of years cooking or heating with wood stoves multiplied by the average number of hours spent daily in the kitchen. ${ }^{9}$ Although the index does not reflect the intensity, it was designed to obtain the association between the presence and absence of airflow obstruction (AFO) or chronic bronchitis. In this sense, it has been very useful in cross-sectional studies. We decided to use this index because this study was designed to identify prevalence rather than intensity of the exposure. As with tobacco smoking, the index of exposure may be used as correlates with different respiratory outcomes.

Smoking history (daily amount, age at beginning and stopping, type of cigarette and current status) was also assessed. This individual questionnaire contained all of the items of the questionnaire that was used in the PLATINO study. ${ }^{4}$

\section{Spirometry}

Functional maneuvers were taken using identical portable, battery-operated, ultrasound transit-time-based EasyOne ${ }^{\mathrm{TM}}$ spirometers (Medical Technologies, Chelmsford, MA, USA). The calibration was checked daily using a $3 \mathrm{~L}$ syringe.
Pre- and postbronchodilator spirometries were performed according to the procedures recommended by the ATS/ERS $2005^{10}$ and using Mexican standard reference equations, ${ }^{11}$ which are similar to the Third National Health and Nutrition Examination Survey values for Mexican-Americans. ${ }^{12}$

The participants performed up to 8 forced expiratory efforts (average 5) to obtain 3 acceptable maneuvers. All spirometric examinations were done with the person seated and wearing a nose clip and a disposable mouthpiece.

The test results were stored in the spirometer memory and downloaded daily to an "online" platform (TraceEPOC) designed for this study. The platform stored all the traces for the spirometry and the values of each maneuver. To determine the validity of each spirometric test, a senior pulmonology specialist reviewed the spirometry tracings online after each working day. The system had a section in which the pulmonologist scored the spirometry for each subject. If the spirometry was not acceptable and was scored as D, E or F, the information was not stored, and the technician was asked to return to the house of the woman for the spirometry to be repeated. For this reason, the technicians had to repeat spirometries for at least 60 different subjects. Health volunteers working in the 8 villages personally provided the spirometry results to each participant, and the subjects with abnormal results were offered a free consultation at a hospital.

\section{Oximetry}

Oxygen saturation $\left(\mathrm{SaO}_{2}\right)$ was measured by using a finger pulse oximeter. The pulse oximeter was placed on the middle or index finger of the right hand of the participant. The technicians made sure that the procedure was performed on a flat surface to prevent the oximeter from moving or coming off. The pulse signal was required to be strong, and the $\mathrm{SaO}_{2}$ reading had to be stable. If not, factors that could affect the reading, as listed earlier, were investigated. In order to achieve stable assessments, the reported $\mathrm{SaO}_{2}$ was obtained after $3 \mathrm{~min}$ of quiet inhalation of room air. Values were recorded as a percentages in the patient's chart.

\section{Statistical analysis}

The data for continuous variables were expressed as mean and SD, and bivariate analyses were performed using unpaired $t$-tests. For discrete variables and ranked variables, a Chi-squared $\left(\chi^{2}\right)$ test was used. Analysis of variance (ANOVA) was performed to compare the lung function as a function of the level of exposure. The statistical analysis was performed using the STATA program (version 12; StataCorp LP, College Station, TX, USA). Because the sampling 
scheme did not allow the estimation of a pooled prevalence of COPD for each location, the analyses were not weighted nor were pooled prevalence values produced.

\section{Results}

The data were collected between September and December 2013. A total of 2,767 houses were visited. No differences were found at the household level among the 8 studied locations in terms of the contact failure rate, which was $22 \%$ (Figure 1). There were 1,888 candidate women, of whom 1,333 completed the questionnaires and from whom 1,190 spirometric evaluations were obtained. The intention to complete the spirometry was high (89.27\%), and 969 (81\%) spirometries were scored as A-C. These represent the whole study group whose general characteristics are shown in Table 1 . The mean age of the subjects was $49.8 \pm 11.1$ years,

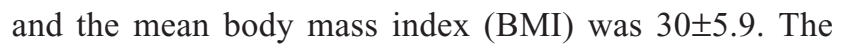
number of years of education was low in 55\% of the participants (534 women had 8 years or less of education or were illiterate). A large majority (62\%) were housewives, and the total family income was $<180$ US dollars a month for 374 women (39\%). The prevalence of exposure to biomass smoke was $47 \%$, whereas $9 \%$ were currently exposed to tobacco smoke (5.14 $\pm 8.3 \mathrm{pack} / \mathrm{year}$ and $4 \pm 5$ cigarettes/day). The age

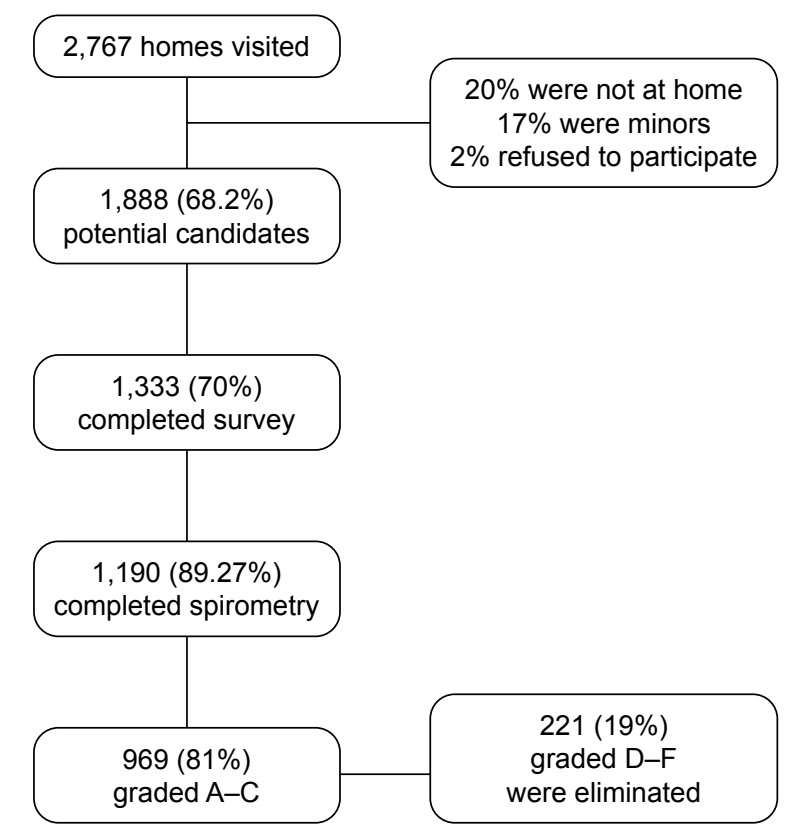

Figure I The scheme represents the universe of the 8 locations in the study and the final spirometries obtained.

Notes: Test Session Quality Grades: $A=3+$ acceptable maneuvers, and FEV, and FVC match within $150 \mathrm{~mL} ; \mathrm{B}=3$ + acceptable maneuvers, and $\mathrm{FEV}$, and FVC match within $200 \mathrm{~mL} ; \mathrm{C}=2$ + acceptable maneuvers, and FEV, and FVC match within $250 \mathrm{~mL}$; $\mathrm{D}=$ only I acceptable maneuver, or the FEV, or the FVC from the best 2 acceptable within $250 \mathrm{~mL}$; $\mathrm{F}=$ no acceptable maneuvers.

Abbreviations: $\mathrm{FEV}_{1}$, forced expiratory volume in the first second; FVC, forced vital capacity.
Table I General characteristics

\begin{tabular}{|c|c|}
\hline Variables & $n=969$ \\
\hline Age, years & $49.8 \pm 11.1$ \\
\hline Weight, kg & $68.8 \pm 13.8$ \\
\hline Height, cm & $|5| \pm 6.6$ \\
\hline $\mathrm{BMI}, \mathrm{kg} / \mathrm{cm}^{2}$ & $30 \pm 5.9$ \\
\hline Normal, n (\%) & $150(15.5)$ \\
\hline Overweight, n (\%) & $369(38.2)$ \\
\hline Obese class I, n (\%) & $304(31.4)$ \\
\hline Obese class II, n (\%) & $98(10.1)$ \\
\hline Obese class III, n (\%) & $46(4.8)$ \\
\hline \multicolumn{2}{|l|}{ Civil status, n (\%) } \\
\hline Married/free union & $713(74)$ \\
\hline \multicolumn{2}{|l|}{ Education in years, $\mathbf{n}(\%)$} \\
\hline $0-2$ & $242(25)$ \\
\hline $3-8$ & $292(30)$ \\
\hline \multicolumn{2}{|l|}{ Occupation, n (\%) } \\
\hline Work outside of home & $332(35)$ \\
\hline Housewife & $599(62)$ \\
\hline \multicolumn{2}{|l|}{ Income (dollars/month), n (\%) } \\
\hline$\leq \$ 180.00$ & $374(39)$ \\
\hline$>\$ 180-500$ & $396(4 I)$ \\
\hline \multicolumn{2}{|l|}{ Exposures, n (\%) } \\
\hline Indoor exposure to biomass for cooking or heating & $458(47)$ \\
\hline Indoor exposure to coal for cooking or heating & $185(19)$ \\
\hline Tobacco current or past exposure & $260(27)$ \\
\hline Pack/years & $3.3 \pm 7.31$ \\
\hline General COPD prevalence, n=969, n (\%) & $24(2.5)$ \\
\hline With biomass exposure, $n=458, n(\%)$ & $14(3.1)$ \\
\hline With coal exposure, $n=185, \mathrm{n}(\%)$ & $4(2.2)$ \\
\hline With biomass/coal exposure, $n=536, n(\%)$ & $15(3.5)$ \\
\hline With tobacco exposure, $n=348, n(\%)$ & $4(1.1)$ \\
\hline
\end{tabular}

Note: Currency is US Dollars.

Abbreviation: BMI, body mass index.

of onset of the biomass exposure was $4 \pm 3$ years, and the age of stopping of the exposure was $47 \pm 18$ years. The prevalence of COPD was $2.5 \%$ for the total population $(n=969)$ and $3.1 \%, 2.2 \%, 3.5 \%$ and $1.1 \%$ for those exposed to biomass only, coal only, biomass and coal, and tobacco smoking, respectively.

Table 2 shows the results of the spirometry according to the extent of the exposure (1-99; 100-199 and 200 or higher hours/years of exposure). The $\mathrm{FEV}_{1}$ and FVC, as either liters or percentage predicted, were significantly lower in the women with the greater exposure levels. The $\mathrm{FEV}_{1} / \mathrm{FVC}$ and $\mathrm{FEV}_{1} /$ forced expiratory volume in the sixth second $\left(\mathrm{FEV}_{6}\right)$ values, as well as the $\mathrm{SaO}_{2}$ values, were also lower in the women who had the greatest exposure. When we analyzed lung function according to age, no trends were found. Table 3 shows the prevalence of RS as functions of biomass exposure. Cough, phlegm, wheezing and dyspnea were significantly more frequent in the women who were exposed to biomass than in those without exposure. Furthermore, when the exposure was classified according to the extent of exposure, 
Table 2 Demographics and lung function according to the extent of biomass exposure

\begin{tabular}{|c|c|c|c|c|}
\hline Variables & Mean \pm SD & Mean \pm SD & Mean \pm SD & $p$-value* \\
\hline$n=458$ & $n=371$ & $n=60$ & $\mathbf{n}=\mathbf{2 7}$ & \\
\hline $\begin{array}{l}\text { Biomass exposure } \\
\text { in hours/years }\end{array}$ & I-99.99 & $100-199.99$ & $200-600$ & \\
\hline \multicolumn{5}{|c|}{ Demographic data } \\
\hline Age, years & $50 \pm 11$ & $60 \pm 12$ & $60 \pm 11$ & 0.000 \\
\hline Weight, kg & $68 \pm 13$ & $66 \pm 14$ & $68 \pm 15$ & 0.720 \\
\hline Height, cm & $149 \pm 7$ & $148 \pm 5$ & $146 \pm 6$ & 0.018 \\
\hline $\begin{array}{l}\text { Abdominal } \\
\text { circumference, } \mathrm{cm}\end{array}$ & $96 \pm 11$ & $97 \pm 12$ & $100 \pm 12$ & 0.169 \\
\hline \multicolumn{5}{|l|}{ Lung function } \\
\hline $\mathrm{FEV}_{1}, \mathrm{~L}$ & $2.44 \pm 0.49$ & $2.09 \pm 0.50$ & $1.86 \pm 0.50$ & 0.000 \\
\hline $\mathrm{FEV}_{1}$, \% pred & $106 \pm 16$ & $103 \pm 18$ & $95 \pm 17$ & 0.004 \\
\hline FVC, L & $2.95 \pm 0.55$ & $2.57 \pm 0.52$ & $2.34 \pm 0.55$ & 0.000 \\
\hline FVC, \% pred & $102 \pm 15$ & $98 \pm 14$ & $93 \pm 15$ & 0.004 \\
\hline $\mathrm{FEV}_{1} / \mathrm{FVC}$ & $83 \pm 5$ & $80 \pm 8$ & $79 \pm 6$ & 0.001 \\
\hline $\mathrm{FEV}_{1} / \mathrm{FEV}_{6}$ & $0.84 \pm 0.04$ & $0.83 \pm 0.03$ & $0.8 I \pm 0.05$ & 0.000 \\
\hline $\mathrm{SaO}_{2} \%$ & $93.4 \pm 3.6 \mathrm{I}$ & $92.8 \mathrm{I} \pm 2.9$ & $91.9 \pm 2.2$ & 0.046 \\
\hline
\end{tabular}

Note: *One-way ANOVA.

Abbreviations: ANOVA, analysis of variance; $\mathrm{FEV}_{1}$, forced expiratory volume in the first second; $\mathrm{FEV}_{6}$, forced expiratory volume in the sixth second; FVC, forced vital capacity; $\%$ pred, percentage predicted; $\mathrm{SaO}_{2}$, oxygen saturation.

the women with the greater exposures showed a significantly higher prevalence of cough, phlegm and dyspnea (Figure 2).

The prevalence of COPD in the women exposed to biomass was $3.1 \%$, whereas in those who were not exposed, it was $2 \%$. There was a significant difference in the tobacco smoking prevalence in the women without biomass exposure (12\%) than in the women exposed to biomass $(5.7 \%)(p<0.0001)$. We also analyzed the association among tobacco smoking, symptoms and lung function (Table 4). No difference was found among tobacco smoking and symptoms. However, as expected, we observed that the higher the tobacco smoking, the lower the lung function in some parameters of the

Table 3 Prevalence of symptoms and prevalence of COPD according to biomass exposure

\begin{tabular}{|c|c|c|c|}
\hline Symptoms & $\begin{array}{l}\text { Biomass } \\
\text { exposure, } \\
\mathrm{n}(\%)\end{array}$ & $\begin{array}{l}\text { Without } \\
\text { biomass } \\
\text { exposure, n (\%) }\end{array}$ & $p$-value \\
\hline Cough & II4 (24) & $94(19)$ & 0.037 \\
\hline Phlegm & I35 (29) & $91(18)$ & 0.0001 \\
\hline Wheezing & $119(25)$ & $80(16)$ & 0.0001 \\
\hline \multicolumn{4}{|l|}{ Dyspnea score } \\
\hline $\mathrm{mMRC} 0$ & I8I (39) & $163(33)$ & 0.051 \\
\hline mMRC I & $128(27)$ & $80(16)$ & 0.0001 \\
\hline $\mathrm{mMRC} 2$ & $74(16)$ & $40(8)$ & 0.0001 \\
\hline $\mathrm{mMRC} 3$ & $60(13)$ & $31(6)$ & 0.001 \\
\hline $\mathrm{mMRC} 4$ & $9(2)$ & $2(0.4)$ & 0.026 \\
\hline COPD prevalence & $14(3.1)$ & $10(2)$ & 0.270 \\
\hline Current smoke & $26(6)$ & $62(12)$ & 0.0001 \\
\hline
\end{tabular}

Note: Unpaired t-test; chi square as appropriate.

Abbreviation: mMRC, Modified Medical Research Council Dyspnea Scale.

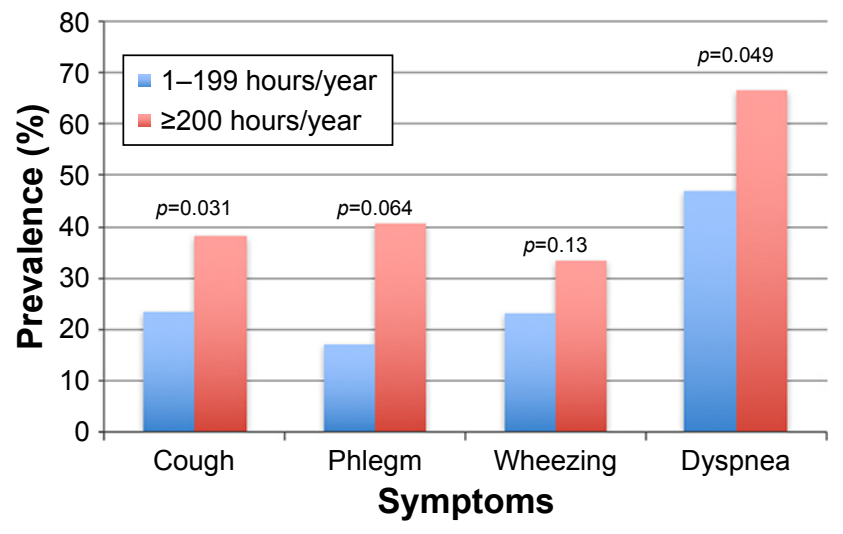

Figure 2 The prevalence of the principal symptoms of COPD, according to the hours of exposure to biomass smoke.

spirometry except for $\mathrm{FEV}_{1}$ and $\mathrm{FVC}$ both in milliliters and percentage predicted (Table 4).

\section{Discussion}

Information on the association of prevalence of COPD with biomass exposure in suburban areas is lacking. This work was designed in a very strategic non-rural area within the metropolis. The search exclusively focused on women aged $>35$ years, who were surveyed to determine the prevalence of COPD, lung function and RS associated with biomass exposure. The main findings were that 1) the prevalence of COPD in a suburban area in women exposed to biomass was $3 \% ; 2$ ) the prevalence of biomass exposure in this suburban

Table 4 Demographics and lung function according to exposure of tobacco smoking

\begin{tabular}{|c|c|c|c|c|}
\hline Variable & Mean \pm SD & Mean \pm SD & Mean \pm SD & $p$-value* \\
\hline$n=260$ & $n=194$ & $n=27$ & $n=39$ & \\
\hline Tobacco index/ & $0-5$ & $5.1-10$ & $>10.1$ & \\
\hline
\end{tabular}

years

Demographic data

$\begin{array}{lllll}\text { Age, years } & 46.48 \pm 10.05 & 47.22 \pm 8.64 & 53.59 \pm 9.65 & 0.000 \\ \text { Weight, kg } & 68.52 \pm 13.33 & 71.52 \pm 14.14 & 69.31 \pm 13.53 & 0.545 \\ \text { Height, cm } & 151.7 \pm 6.2 & 152.81 \pm 9.37 & 151.97 \pm 5.59 & 0.704 \\ \begin{array}{l}\text { Abdominal } \\ \text { circumference, cm }\end{array} & 88.72 \pm 27.33 & 79.18 \pm 39.91 & 90.91 \pm 26.98 & 0.229 \\ \text { Lung function } & & & & \\ \mathrm{FEV}_{1}, \mathrm{~L} & & & & \\ \mathrm{FEV}_{1}, \% \text { pred } & 105.4 \pm \mathrm{I} 4.62 & 104.86 \pm 25.43 & 98.12 \pm 15.26 & 0.038 \\ \mathrm{FVC}, \mathrm{L} & 3.22 \pm 0.53 & 3.23 \pm 0.61 & 2.9 \pm 0.54 & 0.004 \\ \mathrm{FVC}, \% \text { pred } & 105.44 \pm 13.7 & 105.21 \pm 20.87 & 98.81 \pm 13.89 & 0.035 \\ \mathrm{FEV}_{1} / \mathrm{FVC} & 83.82 \pm 4.12 & 82.5 \pm 4.39 & 81.09 \pm 5.94 & 0.002 \\ \mathrm{FEV}_{1} / \mathrm{FEV} & 0.83 \pm 0.04 & 0.82 \pm 0.03 & 0.81 \pm 0.04 & 0.021 \\ \mathrm{SaO}_{2} \% & 93.39 \pm 4.39 & 93.7 \pm 2.53 & 93.14 \pm 3.12 & 0.876\end{array}$

Note: *One-way ANOVA.

Abbreviations: ANOVA, analysis of variance; $\mathrm{FEV}$, forced expiratory volume in the first second; $\mathrm{FEV}_{6}$, forced expiratory volume in the sixth second; $\mathrm{FVC}$, forced vital capacity; \% pred, percentage predicted; $\mathrm{SaO}_{2}$, oxygen saturation. 
area was high, $\sim 47 \%$ of the studied population; 3 ) the subjects' lung function decreased as the intensity of biomass exposure increased; and 4) a substantial number of the exposed women had RS even before having functional damage.

Very little specific and dependable information on the prevalence of COPD secondary to biomass exposure in suburban areas is available. The large majority of information on the prevalence of COPD that is associated with biomass exposure has come from epidemiological and cross-sectional studies in women who live or who have lived in rural areas. ${ }^{13}$ The PLATINO study ${ }^{4}$ reported that the prevalence of biomass exposure in 5 Latin American cities ranged between $29.3 \%$ and $53.9 \%$. However, the survey was not specifically designed to evaluate the biomass exposure, and the prevalence of COPD that was associated with the biomass exposure was not estimated. However, in a post hoc analysis, it was found that the prevalence of COPD in never-smokers was 3.5\%, but this was mainly found in older subjects who had a medical diagnosis of asthma or previous tuberculosis, ${ }^{14}$ meaning that the prevalence of COPD due to biomass was $<3.5 \%$. Li et al studied 317 never-smoker subjects in China to determine the prevalence of AFO and found that this prevalence was $4.0 \%$ in females and $5.1 \%$ in males. ${ }^{13}$ They found an association of the prevalence with coal combustion rather than wood. Unfortunately, no postbronchodilator test was performed on the subjects, and it was therefore not possible to determine whether the subjects were asthmatic or not. Furthermore, half of the described population was not rural. Another study in China ${ }^{15}$ found differences in not only both the whole population prevalence between rural and urban areas $(12.0 \%$ vs 7.4\%) but also a subpopulation of non-smoking women in rural Yunyan with a significantly higher prevalence of COPD than urban Liwang (7.2\% vs 2.5\%).

$\mathrm{BSE}$ and the risk of COPD have been studied and reviewed by Eisner et al. ${ }^{16}$ They showed that the overall odds ratio from 15 different cross-sectional and case-control studies was 2.23 (95\% CI 1.72-2.90). However, the specific prevalence in a targeted population-based sample (women who live in a suburban area), as in the current work, has not been previously described. Considering that according to the PLATINO study, the overall prevalence of COPD in Mexico City is $7.8 \%$, and according to our results COPD prevalence associated with biomass and coal exposure in suburban areas is $3.5 \%$, this exposure may explain $>40 \%$ (3.5\% out of $7.8 \%)$ of global prevalence of COPD in the metropolitan area of Mexico City. This figure is not surprising because it has been estimated that approximately half of the world's population (consistent with the present report) uses solid fuels such as wood, animal dung and crop residues for cooking. These fuels release high levels of multiple pollutants that are similar to those present in tobacco smoke. ${ }^{17}$ Exposure to biomass has been associated with decreased pulmonary function, even prior to having airflow limitations consistent with COPD. ${ }^{18-22}$ For instance, among women who cook with biomass fuels, a study from rural areas in Mexico found that biomass use was associated with a small but significant decrease in $\mathrm{FEV}_{1} / \mathrm{FVC}^{18}$ but not with $\mathrm{FEV}_{1}$, either in milliliters or percentage predicted. This was probably because the extent of exposure to biomass (114.3 \pm 82.6 hours-years) was not as high $(224 \pm 123)$ as we found in this study. Our findings are interesting because they show that the greater the exposure, the greater the decrease in lung function especially in the oldest women, which suggests that as they continue to be exposed to the smoke, the risk to affect their lung function increases. An interesting finding of this study was that in addition to the effects on $\mathrm{FEV}_{1}$, FVC and $\mathrm{FEV}_{1} / \mathrm{FVC}$, the women exposed to biomass also showed decreases in the $\mathrm{FEV}_{1} / \mathrm{FEV}_{6}$ ratio, which has recently been suggested to be as reliable for the diagnosis of AFO as the $\mathrm{FEV}_{1} / \mathrm{FVC}^{23}$

RS may occur before COPD, and lung function reduction appears in women exposed to biomass. In fact, biomass exposure is clearly associated with RS and chronic bronchitis in cross-sectional studies. ${ }^{18,24-33}$ In this study, exposed women showed more frequently the prevalence of cough, phlegm and wheezing. Moreover, a significantly higher prevalence of dyspnea scored as mMRC1 and mMRC2 (27\% and 16\% of the women exposed to biomass had dyspnea compared to $16 \%$ and $8 \%$ in those not exposed) was found. This was one of the reasons why we decided to include younger women in contrast to other prevalence studies on this matter. The aim was to determine if there were more symptoms in younger women with exposure to biomass even if they had no AFO, as has been observed in smokers. ${ }^{34}$ This population as with smokers may also be more susceptible to develop exacerbations and have worse quality of life. Future studies should focus on the impact of symptoms in women with biomass exposure without airflow limitation.

In addition to the reduction of the lung function, the decreases in the $\mathrm{SaO}_{2}$ values and increases in the BMI values paralleled the extent of the biomass exposure in these women.

\section{Limitations}

This work has a few limitations. One is that the included women were younger than those studied in previous reports, and therefore, the period of exposure of our women studied 
was shorter than those studied in other prevalence studies. This may explain the low prevalence observed in this population. In a previous report, the mean age of the women who had COPD associated with exposure to wood smoke was 67 years and their mean time of exposure was 270 hours/years, ${ }^{35}$ whereas in the present study, these values were 53 years and 157 hours/years, respectively. However, the current results showing young women with airflow limitation allow us to speculate about the concept of early COPD prevalence in these women. ${ }^{36,37}$

Another limitation is that, due to the low prevalence of COPD observed in this population, we were not able to perform a robust analysis (multivariate regression analysis) as in previous studies. ${ }^{13,15}$

Finally, we did not investigate for how long they had lived in their present setting nor how many women migrated from their original village to these suburban areas. We only made sure that they had lived at least $\geq 20$ years in their current suburban places.

\section{Conclusion}

This study examined a selected population of women $>35$ years in a suburban area of Mexico City for the prevalence of COPD, biomass exposure and RS. This information is relevant because it confirms previous observations of a causal relationship between biomass and COPD and contributes to demonstrating that the association of COPD with biomass exposure is not only a rural entity but also may be observed in the suburban areas of the big cities.

\section{Data availability}

There are no unpublished data related to this research project. All the data are available upon request to the corresponding author.

\section{Acknowledgment}

This project was sponsored by a non-restricted grant specifically allocated for the care of women with respiratory diseases associated with BSE, by the LXI y LXII legislature of the Chamber of Deputies, through the Commission of Equity and Gender.

\section{Author contributions}

All authors contributed toward data analysis, drafting and revising the paper and agree to be accountable for all aspects of the work.

\section{Disclosure}

The authors report no conflicts of interest in this work.

\section{References}

1. Aryal S, Diaz-Guzman E, Mannino DM. Influence of sex on chronic obstructive pulmonary disease risk and treatment outcomes. Int J Chron Obstruct Pulmon Dis. 2014;9:1145-1154.

2. Vogelmeier CF, Criner GJ, Martinez FJ, et al. Global strategy for diagnosis, management, and prevention of COPD, global initiative for chronic obstructive lung disease 2017 report. GOLD executive summary. Am J Respir Crit Care Med. 2017;195(5):557-582.

3. Lamprecht B, Soriano JB, Studnicka M, et al; BOLD Collaborative Research Group, the EPI-SCAN Team, the PLATINO Team, and the PREPOCOL Study Group. Determinants of underdiagnosis of COPD in national and international surveys. Chest. 2015;148(4):971-985.

4. Menezes AM, Perez-Padilla R, Jardim JR, et al; PLATINO Team. Chronic obstructive pulmonary disease in five Latin American cities (the PLATINO study): a prevalence study. Lancet. 2005;366(9500):1875-1881.

5. Sansores RH, Ramírez-Venegas A, Hernández-Zenteno R, MayarMaya ME, Pérez-Bautista OG, Velázquez Uncal M. Prevalence and diagnosis of chronic obstructive pulmonary disease among smokers at risk. A comparative study of case-finding vs. screening strategies. Respir Med. 2013;107(4):580-586.

6. Salvi S, Barnes PJ. Is exposure to biomass smoke the biggest risk factor for COPD globally? Chest. 2010;138(1):3-6.

7. Hu G, Zhou Y, Tian J, et al. Risk of COPD from exposure to biomass smoke: a metaanalysis. Chest. 2010;138(1):20-31.

8. Buist AS, Vollmer WM, McBurnie MA. Worldwide burden of COPD in high-and low-income countries. Part I. The burden of obstructive lung disease (BOLD) initiative. Int J Tuberc Lung Dis. 2008;12(7): 703-708.

9. Pérez-Padilla JR, Regalado J, Vedal S, et al. Exposure to biomass smoke and chronic airways disease in Mexican women: a Case-Control Study. Am J Respir Crit Care Med. 1996;154(3 pt 1):701-706.

10. Miller MR, Hankinson J, Brusasco V, et al; ATS/ERS Task Force Standardisation of spirometry. Eur Respir J. 2005;26(2):319-338.

11. Pérez-Padilla R, Regalado J, Vázquez García JC. Reproducibilidad espirométrica y adecuación a valores de referencia internacionales en trabajadores mexicanos demandando incapacidad [Reproducibility of spirometry in Mexican workers and international reference values]. Salud Publica Mex. 2001;43(2):113-121. Spanish.

12. Hankinson JL, Odencrantz JR, Fedan KB. Spirometric reference values from a sample of the general US population. Am J Respir Crit Care Med. 1999;159(1):179-187.

13. Li L, Chen Z, Chen J, et al. Prevalence and correlates of airflow obstruction in $~ 317,000$ never-smokers in China. Eur Respir J. 2014; 44(1):66-77.

14. Perez-Padilla R, Fernandez R, Lopez Varela MV, et al. Airflow obstruction in never smokers in five Latin American cities: the PLATINO study. Arch Med Res. 2012;43(2):159-165.

15. Liu S, Zhou Y, Wang X, et al. Biomass fuels are the probable risk factor for chronic obstructive pulmonary disease in rural South China. Thorax. 2007;62(10):889-897.

16. Eisner MD, Anthonisen N, Coultas D, et al; Committee on Nonsmoking COPD, Environmental and Occupational Health Assembly. An official American Thoracic Society public policy statement: novel risk factors and the global burden of chronic obstructive pulmonary disease. Am J Respir Crit Care Med. 2010;182(5):693-718.

17. Salvi SS, Barnes PJ. Chronic obstructive pulmonary disease in nonsmokers. Lancet. 2009;374(9691):733-743.

18. Regalado J, Perez-Padilla R, Sansores R, et al. The effect of biomass burning on respiratory symptoms and lung function in rural Mexican women. Am J Respir Crit Care Med. 2006;174(8):901-905.

19. Saha A, Rao NM, Kulkarni PK, Majumdar PK, Saiyed HN. Pulmonary function and fuel use: a population survey. Respir Res. 2005;6:127. 
20. Rinne ST, Rodas EJ, Bender BS, et al. Relationship of pulmonary function among women and children to indoor air pollution from biomass use in rural Ecuador. Respir Med. 2006;100(7):1208-1215.

21. Malik SK. Domestic cooking, chronic bronchitis and impairment of lung function in rural females. Indian J Chest Dis Allied Sci. 1984; 26(3):200-201.

22. Pandey MR, Regmi HN, Neupane RP, Gautam A, Bhandari DP. Domestic smoke pollution and respiratory function in rural Nepal. Tokai J Exp Clin Med. 1985;10(4):471-481.

23. Perez-Padilla R, Wehrmeister FC, Celli BR, et al; PLATINO Team. Reliability of FEV1/FEV6 to diagnose airflow obstruction compared with FEV1/FVC: the PLATINO longitudinal study. PLoS One. 2013; 8(8):e67960.

24. Albalak R, Frisancho AR, Keeler GJ. Domestic biomass fuel combustion and chronic bronchitis in two rural Bolivian villages. Thorax. 1999; 54(11):1004-1008.

25. Behera D. An analysis of effect of common domestic fuels on respiratory function. Indian J Chest Dis Allied Sci. 1997;39(4):235-243.

26. Behera D, Jindal SK. Respiratory symptoms in Indian women using domestic cooking fuels. Chest. 1991;100(2):385-388.

27. Behera D, Jindal SK, Malhotra HS. Ventilatory function in nonsmoking rural Indian women using different cooking fuels. Respiration. 1994; 61(2):89-92.

28. Kiraz K, Kart L, Demir R, et al. Chronic pulmonary disease in rural women exposed to biomass fumes. Clin Invest Med. 2003;26(5): $243-248$.
29. Pandey MR. Domestic smoke pollution and chronic bronchitis in a rural community of the hill region of Nepal. Thorax. 1984;39(5):337-339.

30. Ellegard A. Cooking fuel smoke and respiratory symptoms among women in low-income areas in Maputo. Environ Health Perspect. 1996;104(9):980-985.

31. Malik SK. Exposure to domestic cooking fuels and chronic bronchitis. Indian J Chest Dis Allied Sci. 1985;27(3):171-174.

32. Akhtar T, Ullah Z, Khan MH, Nazli R. Chronic bronchitis in women using solid biomass fuel in rural Peshawar, Pakistan. Chest. 2007; 132(5):1472-1475.

33. Kalagouda Mahishale V, Angadi N, Metgudmath V, Lolly M, Eti A, Khan S. The prevalence of chronic obstructive pulmonary disease and the determinants of underdiagnosis in women exposed to biomass fuel in India - a Cross Section Study. Chonnam Med J. 2016;52(2): $117-122$.

34. Woodruff PG, Barr RG, Bleecker E, et al; SPIROMICS Research Group. Clinical significance of symptoms in smokers with preserved pulmonary function. $N$ Engl J Med. 2016;374(19):1811-1821.

35. Ramírez-Venegas A, Sansores RH, Pérez-Padilla R, et al. Survival of patients with chronic obstructive pulmonary disease due to biomass smoke and tobacco. Am J Respir Crit Care Med. 2006;173(4):393-397.

36. Svanes C, Sunyer J, Plana E, et al. Early life origins of chronic obstructive pulmonary disease. Thorax. 2010;65(1):14-20.

37. Lange P, Celli B, Agustí A, et al. Lung-function trajectories. Leading to chronic obstructive pulmonary disease. N Engl J Med. 2015;373(2): $111-122$.
International Journal of COPD

\section{Publish your work in this journal}

The International Journal of COPD is an international, peer-reviewed journal of therapeutics and pharmacology focusing on concise rapid reporting of clinical studies and reviews in COPD. Special focus is given to the pathophysiological processes underlying the disease, intervention programs, patient focused education, and self management protocols.

\section{Dovepress}

This journal is indexed on PubMed Central, MedLine and CAS. The manuscript management system is completely online and includes a very quick and fair peer-review system, which is all easy to use. Visit $\mathrm{http}: / / \mathrm{www}$.dovepress.com/testimonials.php to read real quotes from published authors. 